\title{
Research on key measures of Precision Poverty Reduction in Rural Areas
}

\author{
Yuping Zhang and Wenbin Liu \\ Wuhan Technology and Business University, Wuhan,430065,China \\ 812926096@qq.com \\ *The corresponding author
}

Keywords: Poverty reduction; Key measures; Rural areas; Investigation

\begin{abstract}
The majority of Chinese peasants are the basic national conditions, and it is the biggest thing in China to realize the peasants to get rid of poverty and become rich. In order for farmers to live happily, precise poverty reduction measures in rural areas are the key. With effective practical measures suited to local rural areas, farmers can get rid of poverty more effectively.
\end{abstract}

\section{Introduction}

What is precision poverty reduction? Precision poverty reduction refers to the way of poverty control by using scientific and effective procedures to identify, help and manage the poor areas according to the environment of different poverty-stricken areas and the situation of poor farmers. It includes object precision, content precision, target precision, accurate measure, accurate evaluation five content.

\section{The Overall Idea of Precision Poverty Reduction}

The overall idea of precision poverty reduction is to give full play to the role of rural grassroots organizations in fighting fortress and leading, aiming at poor households, targeting poor villages, finding the right root of poverty, implementing poverty reduction by living in peace, helping the poor by industry, helping the poor with intelligence, ensuring poverty reduction, and helping the poor financially. The Party builds six major poverty reduction projects, strengthens the organization and leadership mechanism, the fund guarantee mechanism, the twinning support mechanism, and the supervision and accountability mechanism, and provides all-round assistance to the poor villages and the poor population. Combining poverty reduction with new types of urbanization, industrial development, beautiful rural construction, spiritual civilization construction, and grass-roots organization construction, and making joint efforts to tackle difficulties through wall charts, to ensure the completion of the task of helping the poor with precision in the province.

\section{Target Task of Precision Poverty Reduction}

All Poor Households or all Poor Villages get Rid of Poverty. By the end of 2017, 21800 people and 18 poor villages got rid of poverty in Yicheng, Hubei Province. At the end of 2018, 10000 people and 11 poor villages will get rid of poverty in Yicheng, Hubei Province. All poor households and all poor villages get rid of poverty in Yicheng, Hubei Province.

Income of Poor Households has Increased Significantly. By the end of 2018, poor people with the ability to work have mastered at least one employment entrepreneurship skill, participated in one income increase project, and the annual per capita disposable income exceeded the poverty alleviation criteria set by the state during the same period. And over 50 percent of the average per capita disposable income of local rural residents. All the underage poor can receive fair education, the new generation labor force has the basic quality of transferring employment, and the transmission of poverty between generations has been effectively curbed. Achieve income sources, not worry about food, clothing, housing, education, medical care, pension security. 
Significant Improvement in Production and Living Conditions in Poor Villages. By the end of 2018, the task of rebuilding dilapidated old houses of poor households had been completed in an all-round way, the poor people in areas with poor living conditions had been relocated and resettled as a whole, and the infrastructure of poor villages was relatively perfect. Peasants live and work in peace and contentment to realize the families without dangerous houses. There are secure and stable electricity, radio and television signals, broadband Internet, rural passenger transport. There are safe drinking water, rich income industry, qualified village clinics and doctors, basic public cultural services facilities. The living environment has been significantly improved.

\section{Key Measures for Precision Poverty Reduction}

Accurate Implementation of Poverty Reduction Projects in the Residence. Speeding up the reconstruction of dangerous houses. A plan should be drawn up for the construction of poor villages and the population should be guided to live in a relatively concentrated population. The national funds for the reconstruction of dangerous houses should be given priority to poor households, and the financial subsidy standards for the reconstruction of dangerous houses among poor households should be appropriately raised. By the end of 2018, the housing security of poor households should be comprehensively solved.

To Carry Out Village Environmental Remediation. In combination with the construction of beautiful villages, priority should be given to carrying out environmental sanitation treatment actions focusing on the construction of garbage treatment, sewage treatment and sanitary latrines in poor villages.

Moderate resettlement and relocation. Combined with the new urbanization and rural residential land system reform, the poor people in poor living environment, innovative poverty reduction and relocation mode, exploration of easy development, public housing resettlement, base resettlement and other modes, are given to give policy support to the poor households in the cities and towns.

Addressing production water and safe drinking water. By 2018, the problems and safety of drinking water should be comprehensively and steadily solved in poor villages, and a comprehensive standard of safe drinking water should be achieved. Priority should be given to supporting poor villages in strengthening the construction of small-scale irrigation and water conservancy facilities, innovating the management and protection mechanism of water resources and water conservancy projects in poor villages, making overall use of financial funds and increasing investment in accordance with the principle of division of administrative powers and management of water conservancy projects at different levels. Priority will be given to the key small and small water conservancy projects that meet the requirements of the poor villages and will be included in provincial projects, and will be included in the maintenance, maintenance and construction scope of the central projects.

To ensure safe and stable use of electricity. Investment should be increased in power grid construction in poor villages and priority should be given to upgrading and upgrading of rural power networks in poor villages. By the end of 2018, the problem of producing and living electricity in poor villages and poor households should be completely solved.

To make every effort to improve road traffic conditions. The construction of passenger transport was speeded up from poor villages to all poor villages by the end of 2017. The implementation of the poor village smooth project, on the basis of all administrative villages to cement road, improve the road, industrial road access standards. Overall use of financial funds to support the establishment of village group road maintenance mechanism.

To strengthen communication facilities and electrical business network construction. Full coverage of broadband network signals will be realized in poor villages by 2018 . Priority should be given to the establishment of e-business integrated demonstration points in rural areas in poor villages. By the end of 2018, the integrated service centers and village service points of township-level e-commerce will be fully covered.

Accurate Implementation of the Industrial Poverty Reduction Project. To develop industries according to local conditions. The development of special resources, superior resources and idle 
resources is strengthened in poor areas. Industrial poverty reduction model is actively explored in line with local realities and in relation to the interests of poor households. And This can ensure that poor households share the benefits of resource development reasonably. Preferential support will be given to rural cooperative organizations and agricultural enterprises that attract poor households to obtain employment, participate in shares, and promote income growth in such areas as financial poverty reduction funds and discounted loans for poverty reduction.

To effort to increase property benefits for poor households. The right to use the homestead and the land for collective construction are speeded up the advance. And the property income of the peasants is protected. According to the voluntary principle, through the comprehensive renovation of the rural land, the urban and rural construction land " increase and decrease the hook " and so on , the compensation withdrawal of the house is realized. The capital investment mechanism will be established for poverty reduction resources. In accordance with the principles of quantification to account, stock cooperation, guaranteed bottom dividend, and rolling development, poor households are encouraged to join groups to participate in enterprises and cooperatives in production and operation. The asset potential of the Poor households will be released in the poor villages to the maximum, and the asset income of the poor households is increased.

Vigorously developing Modern Service Industry. The construction of service platforms is accelerated in poor areas. Modern service system is sound. Support has been increased for poor villages from banks, insurance, guarantees and other financial institutions .The coverage of new products is expanded for financial services such as small and micro enterprises development, migrant workers returning home to start their own businesses, college students entrepreneurship, women entrepreneurship, disabled entrepreneurship. The poor villages are vigorously supported to develop new circulation formats such as agricultural super docking, direct supply and marketing, chain operation, etc.

Developing Characteristic Eco-cultural Tourism. The ecological advantages of poor areas should be brought into full play. The principle of "humanity within and ecology outside" should be adhered to. Eco-cultural tourism should be developed. Rural tourism development planning should be scientifically formulated. Tourism resources should be integrated. Regional boundaries should be broken. Tourism infrastructure should be strengthened.

Accurate Implementation of Brain Poverty Reduction Project. In the field of education. The Construction of Rural compulsory Education Standardization should be carried out, and standardization and modernization of distance education should be realized simultaneously.

In the construction of spiritual civilization. The Construction of spiritual Civilization in Poor villages should be strengthened. The construction of cultural and sports facilities in poor villages should be strengthened. The construction of public cultural service center in poor villages should be strengthened.

Accurate Implementation of Social Security Poverty Reduction Project. In the field of social security about pension and employment. The Skills training for the Poor Labor Force should be vigorously carried out. The local development industry, the ability quality of self - development and entrepreneurship should be enhanced. If the poor people who work outside the country are recognized as having difficulty finding employment and participate in social insurance, they may enjoy the social insurance allowance for flexible employment in accordance with the relevant regulations.

In the field of social security about medical and health. Priority should be given to the improvement of health infrastructure and the support of health technical personnel in poor villages as the focus of the work of medical treatment and poverty reduction, and priority should be given to promoting the standardization of health clinics in poor villages.

In the field of social security about civil aid. All the eligible objects in the poor population should be brought into the scope of the minimum living standard in time, and the standard of minimum living standard should be raised in good time to realize the full guarantee under the dynamic conditions. 
Accurate Implementation of Finance Poverty Reduction Project. The financial poverty reduction should be vigorously implemented. The financial poverty reduction insurance mechanism should be innovated. The series of micro-insurance products should be popularized in an all-round way. The mutual benefit between micro-poverty insurance and pro-poor microcredit should be realized. The return of poor groups to poverty as a result of accidents should be prevented.

\section{Acknowledgements}

This research was supported by Open Fund Major bidding Research Project of Hubei Rural Social Management Innovation Research Center in China (Grant No. HNC2015001).

\section{References}

[1] Hong He, Chenglin Lu. Three problems of farmland Circulation in the background of New urbanization[J]. Study and practice, 2015(4), pp.32-38.

[2] Bin Lei. Strategic study on Xiangyang Construction of the Central City of the Hanjiang River Basin[J]. Hubei social science, 2015(3), pp.58-63.

[3] Chongtai Tan, Daoyuan Tang. Rural Financial Development and Rural Economic growth[J]. Jianghan Forum, 2015(1), pp.5-11.

[4]Lihua Wang, Yuliang Gu. Exploration of household registration reform and Citizenization in rural areas[J]. Study and practice, 2015(1), pp.85-93.

[5] En Deng, Gan Zuo . VAR Analysis on the influence of Rural Financial Industry Development on Farmers income in Hunan Province[J]. Hubei social science, 2015(2), pp.74-81.

[6] Peng L, Fang W. Heterogeneity of Inferring Reputation of Cooperative Behaviors for the Prisoners' Dilemma Game [J]. Physica A: Statistical Mechanics and its Applications, 2015, 433: 367-378. 